\title{
CTLA4 tagging polymorphisms and risk of colorectal cancer: a case-control study involving 2,306 subjects
}

\author{
Chen Zou ${ }^{1, *}$ \\ Hao Qiu ${ }^{2, *}$ \\ Weifeng Tang ${ }^{3}$ \\ Yafeng Wang ${ }^{4}$ \\ Bin $\operatorname{Lan}^{5}$ \\ Yu Chen ${ }^{6-8}$ \\ 'Department of General Surgery, Affiliated \\ People's Hospital of Jiangsu University, \\ Zhenjiang, Jiangsu Province, China; \\ ${ }^{2}$ Department of Immunology, School of \\ Medicine, Jiangsu University, Zhenjiang, \\ Jiangsu Province, China; ${ }^{3}$ Department of \\ Cardiothoracic Surgery, Affiliated People's \\ Hospital of Jiangsu University, Zhenjiang, \\ Jiangsu Province, China; ${ }^{4}$ Department \\ of Cardiology, The People's Hospital of \\ Xishuangbanna Dai Autonomous Prefecture \\ Jinghong, Yunnan Province, China; ${ }^{5}$ Shanghai \\ Center for Systems Biomedicine, Shanghai \\ Jiao Tong University, Shanghai, China; \\ ${ }^{6}$ Cancer Bio-immunotherapy Center, \\ Fujian Cancer Hospital and Fujian Medical \\ University Cancer Hospital, Fuzhou, \\ Fujian Province, China; ${ }^{7}$ Fujian Provincial \\ Key Laboratory of Translational Cancer \\ Medicine, Fuzhou, Fujian Province, China; \\ ${ }^{8}$ Department of Medical Oncology, Fujian \\ Cancer Hospital and Fujian Medical \\ University Cancer Hospital, Fuzhou, Fujian \\ Province, China \\ *These authors contributed equally \\ to this work
}

Correspondence: Yu Chen

Department of Medical Oncology, Fujian

Medical University Cancer Hospital \& Fujian

Cancer Hospital, No 420, Fuma Road, Fuzhou 350000 , China

Tel +86 I3859089836

Email chenyu1980@fjmu.edu.cn

Bin Lan

Shanghai Center for Systems Biomedicine,

Shanghai Jiao Tong University, No. 800 Dong

Chuan Rd, Minhang, Shanghai 200240, China

Tel +86 I39l7 742604

Email lanbin@sjtu.edu.cn
This article was published in the following Dove Press journal:

OncoTargets and Therapy

Background: CTLA4 is a candidate gene which has been implicated in the development of colorectal cancer (CRC).

Patients and Methods: To determine the important role of CTLA-4 polymorphisms on risk of CRC, we genotyped four CTLA-4 tagging polymorphisms and calculated crude/adjusted ORs with their 95\% CIs. We recruited 1,003 sporadic CRC cases and 1,303 controls.

Results: The findings suggested that CTLA-4 rs231775 G>A polymorphism increased the risk of $\mathrm{CRC}$ (homozygote model: adjusted $\mathrm{OR}=1.40,95 \% \mathrm{CI}=1.05-1.87, P=0.022$; dominant model: adjusted $\mathrm{OR}=1.19,95 \% \mathrm{CI}=1.00-1.41, P=0.047$; and recessive model: adjusted $\mathrm{OR}=1.38,95 \% \mathrm{CI}=1.05-1.82, P=0.021)$. In a stratified analysis by site of tumor, this association was also found in colon cancer. We also found that CTLA-4 rs231775 GA/AA genotypes might be associated with an increased risk of CRC in Zhenjiang cohort. In addition, we found the CTLA-4 rs16840252 C > T polymorphism was associated with the risk of colon cancer. Haplotype comparison analysis showed that CTLA-4 $\mathrm{G}_{\mathrm{rs} 3087243} \mathrm{C}_{\mathrm{rs} 16840252} \mathrm{C}_{\mathrm{rs} 733618}$ $\mathrm{A}_{\mathrm{rs} 231775}, \mathrm{G}_{\mathrm{rs} 3087243} \mathrm{C}_{\mathrm{r} 16840252} \mathrm{~T}_{\mathrm{rs} 733618} \mathrm{~A}_{\mathrm{rs} 231775}$, and other haplotypes increased the risk of CRC $(P<0.001,<0.001$, and 0.002 , respectively).

Conclusion: This study evidences an association of CTLA-4 tagging polymorphisms and haplotypes with CRC risk. Additional well-designed studies with large sample sizes are required to confirm our findings.

Keywords: polymorphism, immune, CTLA-4, tagging, colorectal cancer, susceptibility

\section{Introduction}

Colorectal cancer (CRC) is one of the most common malignancies and is becoming the fifth leading cause of cancer death in China. ${ }^{1}$ It is reported that the incidence rate and CRC-related mortality are increasing rapidly worldwide., ${ }^{2,3}$ These may be attributed to certain lifestyles and environmental factors, including physically inactive, overweight, smoking, and drinking. Recently, Katsidzira et $\mathrm{al}^{4}$ reported that diabetes mellitus, previous schistosomiasis, approximation to a western lifestyle, and family history were the predominant associations with CRC. Besides these unhealthy lifestyle and environmental risk factors, genetic factors may also affect the development of CRC. A previous study demonstrated that genetic risk factors may contribute to $\sim 35 \%$ etiology of CRC cases. ${ }^{5} \mathrm{Up}$ to now, the inherited factor of CRC remains controversial. Recently, a number of investigations have been devoted to exploring the potential molecular mechanism of CRC carcinogenesis, and inherited factors have been considered to play a vital role in the occurrence and development of CRC. ${ }^{6,7}$ Investigations 
of these conceivable inherited factors may enrich our view on the etiology of CRC.

The cytotoxic T-lymphocyte antigen-4 (CTLA-4) gene, also named as a cluster of differentiation 152 (CD152), is one of the costimulatory molecule genes involved in immune response. CTLA-4 is transiently expressed on some activated T cells. ${ }^{8}$ The expression of CTLA-4 inhibits cytokine production of $\mathrm{T}$ cells and then provides a negative signal to T cells..$^{9,10}$ The structure of CTLA-4 shares some homologies with CD28 and binds to B7.1 and B7.2 ligands competitively. However, CTLA-4 has a higher binding affinity with B7 molecules compared with CD28. Through interaction of CTLA-4 with B7 molecules, T-cell proliferation, activation, and cytokine production can be inhibited. ${ }^{11-13}$ The CTLA-4 gene is located in chromosome $2 \mathrm{q} 33$, which belongs to several immune regulatory gene regions. Since CTLA-4 acts as a vital regulatory factor for some immune responses, any genetic variation in $C T L A-4$ gene may influence normal immune function and then alter the risk of cancer. Hence, exploring the impact of these genetic variations in CTLA-4 gene could determine their relationship with cancer susceptibility. CTLA-4 is polymorphic and contains more than 100 single-nucleotide polymorphisms (SNPs). Among them, some SNPs (eg, rs3087243 G>A, rs16840252 C>T, rs4553808 $\mathrm{T}>\mathrm{C}$, rs5742909 $\mathrm{C}>\mathrm{T}$, rs733618 $\mathrm{T}>\mathrm{C}$, and rs231775 $\mathrm{G}>\mathrm{A}$ polymorphisms) in CTLA-4 gene were extensively studied and were reported to be correlated with risk of human malignancy. ${ }^{14,15}$ Some case-control studies explored the relationship between CTLA-4 polymorphisms and $\mathrm{CRC} ;{ }^{16,17}$ however, the sample sizes were limited and the results remained conflicting.

The evasion of immune surveillance and the production of immunosuppressive cytokines are two of the most common immune defects identified to be correlated with CRC. $C T L A-4$ is a candidate gene which has been implicated in immune response. ${ }^{18}$ Moreover, due to the emerging role of CTLA-4 as an immune checkpoint molecule, anti-CTLA-4 antibody has been tested recently in the treatment of CRC patients. ${ }^{19}$ Previous case-control studies, conducted in diverse population to assess the relationship of CRC with CTLA-4 polymorphisms, have generated conflicting findings. Hence, we undertook a study to determine whether CTLA-4 variations could cause a predisposition toward CRC. In this study, we analyzed the tagging SNPs of CTLA-4 (rs3087243 $\mathrm{G}>\mathrm{A}, \mathrm{rs} 16840252 \mathrm{C}>\mathrm{T}, \mathrm{rs} 733618 \mathrm{~T}>\mathrm{C}$, and $\mathrm{rs} 231775$ $\mathrm{G}>\mathrm{A}$ polymorphisms) and identified whether these SNPs confer susceptibility to CRC in an Eastern Chinese Han population.

\section{Patients and methods Study population and patient selection}

The study population consisted of 2,306 subjects (1,003 diagnosed as sporadic CRC and 1,303 controls) between October 2014 and August 2017. Among them, 757 CRC patients and 680 controls were enrolled from the Affiliated Union Hospital of Fujian Medical University (Fuzhou, China), and 246 CRC patients and 623 controls were enrolled from the Affiliated People's Hospital of Jiangsu University (Zhenjiang, China). CRC was confirmed via pathology. The age of $\mathrm{CRC}$ cases ranged from 21 to 90 years old (mean age at diagnosis was $61.10 \pm 12.17$ years). The major exclusion criteria were autoimmune disorders, hereditary nonpolyposis CRC, and history of another malignancy. CRC cases who had received neoadjuvant chemoradiotherapy were also excluded. The age of controls ranged from 21 to 87 years old (mean age at sampling was $61.40 \pm 9.61$ years). In this study, the cancerfree controls included 1,303 healthy volunteers who participated in a routine examination in hospitals mentioned above. The primary information of the participants was collected by a pre-structured questionnaire. The definitions of "ever smokers" and "ever drinkers" are described in our previous study. ${ }^{20}$ In addition, according to the criterion for overweight and obesity, a body mass index (BMI) of 24 was used as the cutoff point in Chinese adults. ${ }^{21,22}$ Each participant was informed about the present study and signed a standard informed consent form. The Ethical Committee of Fujian Medical University and Jiangsu University approved the protocols of the study (No KY-2013-11 and No 2012-00-18, respectively).

\section{Data collection}

All participants were personally questioned by two experienced doctors. The questionnaire included the primary information about demographics (eg, age, sex), smoking, drinking, height, and weight (Table 1). The clinical and pathological information of CRC cases was collected from their medical records.

\section{Selection of tagging SNPs}

The tagging SNPs across the entire region of CTLA-4 gene (16.2 kbp spanning from 203862788-203878960 in chromosome 2 [upstream and downstream of gene extending $5 \mathrm{~kb}$, respectively]) were selected from the Chinese Han in Beijing cohort via the HapMap Project (http://hapmap.ncbi.nlm.nih. gov/index.html.en) and analyzed with Haploview 4.2 software using a pairwise linkage disequilibrium (LD) $r^{2}$ threshold 
Table I Distribution of selected demographic variables and risk factors in CRC cases and controls

\begin{tabular}{|c|c|c|c|c|c|}
\hline \multirow[t]{2}{*}{ Variable } & \multicolumn{2}{|c|}{ Cases $(n=I, 003)$} & \multicolumn{2}{|c|}{ Controls $(n=I, 303)$} & \multirow[t]{2}{*}{$P$-value ${ }^{a}$} \\
\hline & $\mathbf{n}$ & $\%$ & $\mathbf{n}$ & $\%$ & \\
\hline Age (years), M ( $\pm S D)$ & $61.10( \pm 12.17)$ & & $61.40( \pm 9.61)$ & & 0.496 \\
\hline Age (years) & & & & & 0.605 \\
\hline$<61$ & 451 & 44.97 & 600 & 46.05 & \\
\hline$\geq 61$ & 552 & 55.03 & 703 & 53.95 & \\
\hline Sex & & & & & 0.867 \\
\hline Male & 620 & 61.81 & 801 & 61.47 & \\
\hline Female & 383 & 38.19 & 502 & 38.53 & \\
\hline Smoking status & & & & & 0.002 \\
\hline Never & 744 & 74.18 & $\mathrm{I}, 038$ & 79.66 & \\
\hline Ever & 259 & 25.82 & 265 & 20.34 & \\
\hline Alcohol use & & & & & $<0.001$ \\
\hline Never & 829 & 82.65 & 1,167 & 89.56 & \\
\hline Ever & 174 & 17.35 & 136 & 10.44 & \\
\hline BMI $\left(k g / m^{2}\right)$ & & & & & $<0.001$ \\
\hline$<24$ & 670 & 66.80 & 688 & 52.80 & \\
\hline$\geq 24$ & 333 & 33.20 & 615 & 47.20 & \\
\hline \multicolumn{6}{|l|}{ Primary site of tumor } \\
\hline Colon cancer & 431 & 42.97 & & & \\
\hline Rectum cancer & 572 & 57.03 & & & \\
\hline \multicolumn{6}{|l|}{ Degree of differentiation } \\
\hline Poorly differentiated & 124 & 12.36 & & & \\
\hline Moderately differentiated & 832 & 82.95 & & & \\
\hline Well differentiated & 47 & 4.69 & & & \\
\hline \multicolumn{6}{|l|}{ Lymph node status } \\
\hline Positive & 518 & 51.65 & & & \\
\hline Negative & 485 & 48.35 & & & \\
\hline \multicolumn{6}{|l|}{ AJCC TMN stage } \\
\hline $0-1$ & 167 & 16.65 & & & \\
\hline II & 290 & 28.91 & & & \\
\hline III & 420 & 41.87 & & & \\
\hline IV & 126 & 12.56 & & & \\
\hline
\end{tabular}

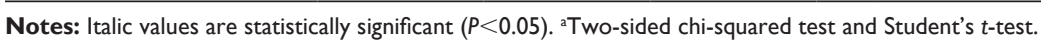

Abbreviations: CRC, colorectal cancer; SD, standard deviation; BMI, body mass index; AJCC, American Joint Committee on Cancer.

of 0.8 between SNPs (with a minimum LD of $r^{2}>0.8$ ). SNPs with a Hardy-Weinberg equilibrium (HWE) $P \geq 0.05$, minor allele frequency $(\mathrm{MAF}) \geq 0.05$, and call rate $\geq 95 \%$ in the CHB cohort were included ${ }^{23}$ The detailed information of the selected four SNPs is summarized in Table 2.

\section{DNA extraction and genotyping}

Ethylenediamine tetraacetic acid (EDTA)-anticoagulated intravenous blood was collected after an overnight fast. The genomic DNA was isolated using the Promega DNA Blood Mini Kit (Promega, Madison, WI, USA).

Table 2 Primary information for CTLA-4 polymorphisms

\begin{tabular}{|c|c|c|c|c|}
\hline Genotyped SNPs & $\begin{array}{l}\text { CTLA-4 rs3087243 } \\
\text { G }>\text { A }\end{array}$ & $\begin{array}{l}\text { CTLA-4 rs23I775 } \\
\mathbf{G}>\mathbf{A}\end{array}$ & $\begin{array}{l}\text { CTLA-4 rsI } 6840252 \\
\mathrm{C}>\mathrm{T}\end{array}$ & $\begin{array}{l}\text { CTLA-4 rs7336 I8 } \\
\mathrm{T}>\mathrm{C}\end{array}$ \\
\hline Chromosome & 2 & 2 & 2 & 2 \\
\hline Function & nearGene-3 & Missense & nearGene-5 & nearGene-5 \\
\hline Location & Intron $3+6,230$ & Exon $1+49$ & Promoter II47 & Promoter 1722 \\
\hline Chr Pos (Genome Build 38) & 203874196 & 203867991 & 203866796 & 203866221 \\
\hline MAF for Chinese in database & 0.183 & 0.314 & 0.122 & 0.390 \\
\hline MAF in our controls $(n=I, 303)$ & 0.189 & 0.305 & 0.117 & 0.412 \\
\hline$P$-value for HWE test in our controls & $0.4 \mathrm{II}$ & 0.430 & 0.065 & 0.335 \\
\hline Genotyping method & SNPscan & SNPscan & SNPscan & SNPscan \\
\hline \% Genotyping value & $98.87 \%$ & $98.79 \%$ & $98.87 \%$ & $98.87 \%$ \\
\hline
\end{tabular}

Abbreviations: SNP, single-nucleotide polymorphism; MAF, minor allele frequency; HWE, Hardy-Weinberg equilibrium. 
The genotyping of the CTLA-4 rs3087243 G>A, rs $16840252 \mathrm{C}>\mathrm{T}$, rs $733618 \mathrm{~T}>\mathrm{C}$, and rs $231775 \mathrm{G}>\mathrm{A}$ polymorphisms were performed by a custom-by-design 48-Plex SNPscan Kit (Genesky Biotechnologies Inc., Shanghai, China) as described in previous studies. ${ }^{24,25}$ This 48-Plex SNPscan Kit was based on double ligation and multiplex fluorescence PCR. ${ }^{26}$ For quality control, 92 (4\%) samples were randomly selected and were tested again by the same genotyping method. The accordance ratio was $100 \%$.

\section{Statistical analysis}

Statistical analysis was performed using SAS version 9.4 software package for Windows (SAS Institute, Cary, NC, USA), and a $P<0.05$ (two-tailed) was considered for level of significance. The continuous variables were expressed as mean $\pm \mathrm{SD}$. We used the Student's $t$-test to check the differences for normally distributed continuous variables between CRC cases and controls. We used the chi-squared test to determine the differences in demographic variables, risk factors (smoking, BMI, and drinking), and the frequencies of genotype between CRC cases and controls. An internetbased calculator program (http://ihg.gsf.de/cgi-bin/hw/ hwa1.pl) was harnessed to examine the deviation of HWE. ${ }^{14}$ Multivariate logistic regression was used to analyze the associations between CTLA-4 rs3087243 G $>$ A, rs 16840252 $\mathrm{C}>\mathrm{T}, \mathrm{rs} 733618 \mathrm{~T}>\mathrm{C}$, and $\mathrm{rs} 231775 \mathrm{G}>\mathrm{A}$ SNPs and risk of CRC. The relationships between CTLA-4 rs3087243 G>A, rs $16840252 \mathrm{C}>\mathrm{T}$, rs733618 $\mathrm{T}>\mathrm{C}$, and $\mathrm{rs} 231775 \mathrm{G}>\mathrm{A}$ polymorphisms genotypes and risk of CRC were assessed by crude/adjusted ORs and the corresponding 95\% CIs when appropriate. The relationships were assessed in additive, homozygote, dominant, and recessive models. We used a Bonferroni correction to adjust for multiple testing..$^{27,28}$

\section{Results}

\section{Demographic characteristics}

In our study, 1,003 CRC patients were included. Of them, 620 were males (61.81\%) and 383 were females (38.19\%). The mean age and SD were $61.10 \pm 12.17$ years. The primary tumor site was the colon in $431(42.97 \%)$ patients and the rectum in $572(57.03 \%)$ patients. For the control group, we recruited 1,303 non-cancer controls, 801 males (61.47\%) and 502 females (38.53\%). Their age mean \pm SD was $61.40 \pm 9.61$ years. All participants were Chinese Han population. The differences of age and sex between CRC and control groups were not statistically significant $(P \geq 0.05)$ (Table 1). As summarized in Table 1, significant differences were found on alcohol consumption, smoking status, and
BMI between the cases and the controls $(P=0.002,<0.001$, and $<0.001$, respectively). The primary information for CTLA-4 rs733618 T>C, rs3087243 G>A, rs16840252 $\mathrm{C}>\mathrm{T}$, and rs231775 G>A SNPs is shown in Table 2. For these SNPs, the successful ratio was more than $98.50 \%$. In controls, MAF of CTLA-4 tagging SNPs was very close to the MAF data for Chinese (Table 2). Table 2 shows the genotype frequencies of CTLA-4 tagging SNPs polymorphisms were all in HWE.

\section{Association of CTLA-4 rs3087243 G>A, rsl6840252 C $>$ T, rs7336I8 T $>C$, and rs23I775 G $>$ A polymorphisms with CRC in overall analysis}

The frequencies of CTLA-4 rs733618 TT, TC, and CC genotypes were $35.31 \%, 47.35 \%$, and $17.35 \%$ in the CRC group and $35.23 \%, 47.15 \%$, and $17.62 \%$ in the control group, respectively (Table 3). The frequencies of CTLA-4 rs $16840252 \mathrm{CC}, \mathrm{CT}$, and TT genotypes were $75.71 \%$, $22.76 \%$, and $1.53 \%$ in the CRC group and $77.38 \%, 21.77 \%$, and $0.85 \%$ in controls, respectively (Table 3 ). There was no statistically significant difference in genotype distribution of CTLA-4 rs16840252 C $>\mathrm{T}$ and rs733618 $\mathrm{T}>\mathrm{C}$ polymorphisms among CRC patients and controls. The frequencies of CTLA-4 rs3087243 GG, GA, and AA genotypes were $65.00 \%, 30.20 \%$, and $4.80 \%$ in the CRC group and $65.38 \%$, $31.38 \%$, and $3.23 \%$ in controls, respectively (Table 3 ). The CTLA-4 rs3087243 AA genotype was associated with a borderline statistically increased risk of CRC, compared with CTLA-4 rs3087243 GG/GA genotypes (crude OR=1.51, 95\% CI=0.99-2.31, $P=0.058$ ). When adjusted for age, sex, BMI, smoking, and drinking, a borderline statistically increased risk of CRC was also found (crude OR $=1.52,95 \%$ $\mathrm{CI}=0.99-2.34, P=0.058$; Table 4).

The frequencies of CTLA-4 rs 231775 GG, GA, and AA genotypes were $42.59 \%, 45.25 \%$, and $12.16 \%$ in the CRC group and $47.77 \%, 43.31 \%$, and $8.85 \%$ in the control group, respectively (Table 3 ). When compared with the CTLA-4 rs231775 GG genotype, CTLA-4 rs231775 AA and GA/AA genotypes significantly increased the risk of CRC (homozygote model: crude $\mathrm{OR}=1.47,95 \% \mathrm{CI}=1.10-1.95$, $P=0.008$; and dominant model: crude $\mathrm{OR}=1.23,95 \%$ $\mathrm{CI}=1.05-1.46, P=0.014)$. When compared with $C T L A-4$ rs231775 GG/GA genotypes, the CTLA-4 rs231775 AA genotype also increased the risk of $\mathrm{CRC}$ (crude $\mathrm{OR}=1.43$, $95 \% \mathrm{CI}=1.09-1.87, P=0.011$ ). When adjusting for age, sex, BMI, smoking, and drinking, the results were not essentially changed (homozygote model: adjusted $\mathrm{OR}=1.40$, 
Table 3 The frequencies of CTLA-4 rs3087243 G>A, rsI6840252 C>T, rs7336I8 T>C, and rs23I775 G>A polymorphisms in CRC patients and controls

\begin{tabular}{|c|c|c|c|c|c|c|c|c|}
\hline \multirow[t]{2}{*}{ Genotype } & \multicolumn{2}{|c|}{$\begin{array}{l}\text { CRC cases } \\
(n=1,003)\end{array}$} & \multicolumn{2}{|c|}{$\begin{array}{l}\text { Colon cancer } \\
(n=431)\end{array}$} & \multicolumn{2}{|c|}{$\begin{array}{l}\text { Rectum cancer } \\
(n=572)\end{array}$} & \multicolumn{2}{|c|}{$\begin{array}{l}\text { Controls } \\
(n=1,303)\end{array}$} \\
\hline & $\mathbf{n}$ & $\%$ & $\mathbf{n}$ & $\%$ & $\mathbf{n}$ & $\%$ & $\mathbf{n}$ & $\%$ \\
\hline \multicolumn{9}{|c|}{ rs3087243 G>A } \\
\hline GG & 637 & 65.00 & 271 & 64.07 & 366 & 65.7I & 850 & 65.38 \\
\hline GA & 296 & 30.20 & 132 & 31.21 & 164 & 29.44 & 408 & 31.38 \\
\hline AA & 47 & 4.80 & 20 & 4.73 & 27 & 4.85 & 42 & 3.23 \\
\hline A allele & 390 & 19.90 & 172 & 20.33 & 218 & 19.57 & 492 & 18.92 \\
\hline \multicolumn{9}{|c|}{ rsl6840252 C>T } \\
\hline $\mathrm{CC}$ & 742 & 75.7I & 319 & $75.4 I$ & 423 & 75.94 & $\mathrm{I}, 006$ & 77.38 \\
\hline $\mathrm{CT}$ & 223 & 22.76 & 94 & 22.22 & 129 & 23.16 & 283 & 21.77 \\
\hline TT & 15 & 1.53 & 10 & 2.36 & 5 & 0.90 & 11 & 0.85 \\
\hline T allele & 253 & 12.91 & 114 & 13.48 & 139 & 12.48 & 305 & 11.73 \\
\hline \multicolumn{9}{|c|}{ rs7336I8 T >C } \\
\hline TT & 346 & 35.31 & 140 & 33.10 & 206 & 36.98 & 458 & 35.23 \\
\hline TC & 464 & 47.35 & 216 & 51.06 & 248 & 44.52 & 613 & 47.15 \\
\hline $\mathrm{CC}$ & 170 & 17.35 & 67 & 15.84 & 103 & 18.49 & 229 & 17.62 \\
\hline C allele & 804 & 41.02 & 350 & 41.37 & 454 & 40.75 & $|, 07|$ & 41.19 \\
\hline \multicolumn{9}{|c|}{$r s 231775 \mathrm{G}>A$} \\
\hline GG & 417 & 42.59 & 178 & 42.18 & 239 & 42.91 & 621 & 47.77 \\
\hline GA & 443 & 45.25 & 187 & 44.31 & 256 & 45.96 & 563 & 43.31 \\
\hline$A A$ & 119 & 12.16 & 57 & $|3.5|$ & 62 & 11.13 & 115 & 8.85 \\
\hline$A$ allele & 681 & 34.78 & 301 & 35.66 & 380 & 34.11 & 793 & 30.50 \\
\hline
\end{tabular}

Abbreviation: CRC, colorectal cancer.

95\% CI=1.05-1.87, $P=0.022$; dominant model: adjusted $\mathrm{OR}=1.19,95 \% \mathrm{CI}=1.00-1.41, P=0.047$; and recessive model: adjusted $\mathrm{OR}=1.38,95 \% \mathrm{CI}=1.05-1.82, P=0.021$; Table 4).

\section{Association of CTLA-4 rs3087243 G>A, rs I6840252 C $>$ T, rs7336I8 T $>C$, and rs23I775 G $>$ A polymorphisms with $C R C$ in a stratification group by primary site of tumor}

To determine whether the effect of CTLA-4 tagging SNPs was modified by the primary site of tumor, we performed a stratified analysis. For CTLA-4 rs16840252 C > T, stratified analysis revealed this polymorphism was associated with an increased risk of colon cancer (homozygote model: adjusted $\mathrm{OR}=2.51,95 \% \mathrm{CI}=1.04-6.03, P=0.040$ and recessive model: adjusted $\mathrm{OR}=2.54,95 \% \mathrm{CI}=1.06-6.09, P=0.037$; Table 4). For the CTLA-4 rs231775 $\mathrm{G}>\mathrm{A}$ polymorphism, we found that CTLA-4 rs231775 AA genotypes might be associated with an increased risk of colon cancer (homozygote model: adjusted $\mathrm{OR}=1.61,95 \% \mathrm{CI}=1.12-2.30, P=0.010$ and recessive model: adjusted $\mathrm{OR}=1.59,95 \% \mathrm{CI}=1.13-2.23, P=0.009$; Table 4). The results of other genetic comparisons are summarized in Table 4.
Association of CTLA-4 rs3087243 $\mathrm{G}>\mathrm{A}, \mathrm{rs}$ I $6840252 \mathrm{C}>\mathrm{T}, \mathrm{rs} 733618 \mathrm{~T}>\mathrm{C}$, and rs23I775 G $>$ A polymorphisms with CRC in a stratification group by geographical area

In this study, CRC patients and controls were enrolled from two different geographical areas (Fuzhou and Zhenjiang, China). We performed a stratified analysis according to geographical area. Compared with CTLA-4 rs231775 GG, we found CTLA-4 rs231775 GA/AA genotypes might be associated with an increased risk of $\mathrm{CRC}$ in the Zhenjiang cohort (adjusted $\mathrm{OR}=1.38,95 \% \mathrm{CI}=1.01-1.88, P=0.041$; Table 5). In addition, the stratified analysis revealed the CTLA-4 rs231775 G>A polymorphism also had a tendency of increased risk to $\mathrm{CRC}$ in the Fuzhou cohort (recessive model: adjusted $\mathrm{OR}=1.40,95 \% \mathrm{CI}=0.99-1.98, P=0.061$; Table 5).

\section{SNP haplotypes}

Using an expectation-maximization algorithm (SHESIS program; Bio-X Inc., Shanghai, China, http://analysis. bio-X.cn/myAnalysis.php), ${ }^{29}$ we constructed seven haplotypes (Table 6). Haplotype comparison analysis suggested that CTLA4 $\mathrm{G}_{\mathrm{rs} 3087243} \mathrm{C}_{\mathrm{rs} 16840252} \mathrm{C}_{\mathrm{rs} 733618} \mathrm{~A}_{\mathrm{rs} 231775}$, 


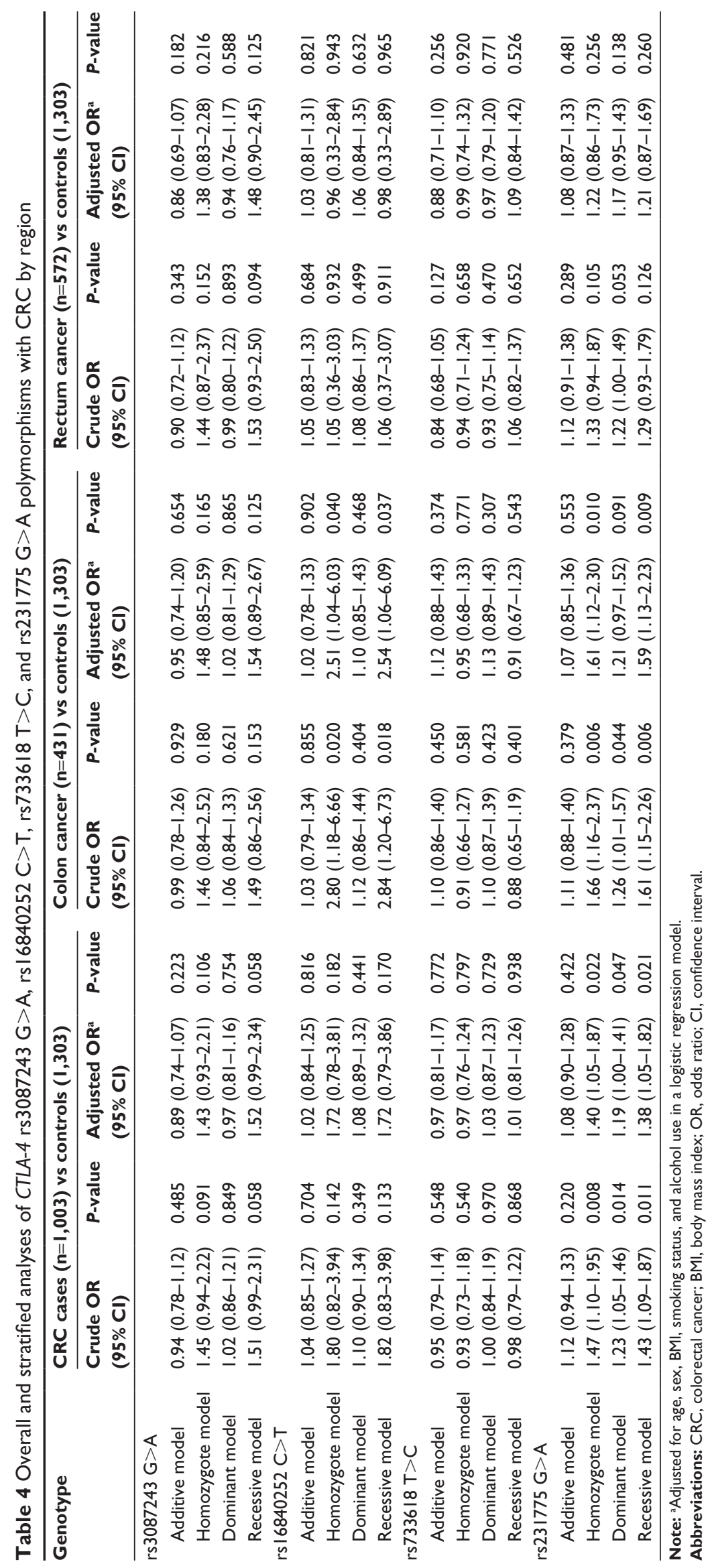


Table 5 Logistic regression analyses of associations between CTLA-4 polymorphisms and risk of CRC in two cohorts

\begin{tabular}{|c|c|c|c|c|c|c|c|c|c|c|c|c|}
\hline \multirow[t]{3}{*}{ Genotype } & \multicolumn{6}{|c|}{ Zhenjiang cohort } & \multicolumn{6}{|c|}{ Fuzhou cohort } \\
\hline & \multicolumn{2}{|c|}{$\begin{array}{l}\text { Cases } \\
(n=246)\end{array}$} & \multicolumn{2}{|c|}{$\begin{array}{l}\text { Controls } \\
(n=623)\end{array}$} & \multirow[t]{2}{*}{$\begin{array}{l}\text { Adjusted OR } \\
(95 \% \mathrm{CI})\end{array}$} & \multirow[t]{2}{*}{$P$-value } & \multicolumn{2}{|c|}{$\begin{array}{l}\text { Cases } \\
(n=757)\end{array}$} & \multicolumn{2}{|c|}{$\begin{array}{l}\text { Controls } \\
(n=680)\end{array}$} & \multirow[t]{2}{*}{$\begin{array}{l}\text { Adjusted OR } \\
(95 \% \mathrm{Cl})\end{array}$} & \multirow[t]{2}{*}{$P$-value } \\
\hline & $\mathbf{n}$ & $\%$ & n & $\%$ & & & n & $\%$ & $\mathbf{n}$ & $\%$ & & \\
\hline \multicolumn{13}{|c|}{$r s 23 \mid 775 \mathrm{G}>A$} \\
\hline GG & 100 & 42.37 & 319 & 51.37 & 1.00 & & 317 & 42.66 & 302 & 44.54 & 1.00 & \\
\hline GA & 110 & 46.61 & 251 & 40.42 & $1.21(0.88-1.66)$ & 0.241 & 333 & 44.82 & 312 & 46.02 & $0.93(0.74-1.17)$ & 0.526 \\
\hline $\mathrm{AA}$ & 26 & 11.02 & 51 & 8.21 & $1.50(0.88-2.55)$ & 0.135 & 93 & 12.52 & 64 & 9.44 & $1.32(0.92-1.90)$ & 0.138 \\
\hline $\mathrm{GA}+\mathrm{AA}$ & 136 & 57.63 & 302 & 48.63 & $1.38(1.01-1.88)$ & 0.041 & 426 & 57.34 & 376 & 55.46 & I.03 $(0.83-1.29)$ & 0.765 \\
\hline $\mathrm{GG}+\mathrm{GA}$ & 210 & 88.98 & 570 & 91.79 & 1.00 & & 650 & 87.48 & 614 & 90.56 & 1.00 & \\
\hline $\mathrm{AA}$ & 26 & 11.02 & 51 & 8.21 & $\mathrm{I} .45(0.87-2.4 \mathrm{I})$ & 0.155 & 93 & 12.52 & 64 & 9.44 & $1.40(0.99-1.98)$ & 0.061 \\
\hline A allele & 162 & 34.32 & 353 & 28.42 & & & 519 & 34.93 & 440 & 32.45 & & \\
\hline \multicolumn{13}{|c|}{$\mathrm{rsl} 16840252 \mathrm{C}>\mathrm{T}$} \\
\hline $\mathrm{CC}$ & 175 & 74.15 & 478 & 76.97 & 1.00 & & 567 & 76.21 & 528 & 77.76 & 1.00 & \\
\hline $\mathrm{CT}$ & 59 & 25.00 & 137 & 22.06 & $1.08(0.76-1.55)$ & 0.656 & 164 & 22.04 & 146 & 21.50 & $1.05(0.81-1.36)$ & 0.721 \\
\hline $\mathrm{TT}$ & 2 & 0.85 & 6 & 0.97 & $0.81(0.16-4.12)$ & 0.800 & 13 & 1.75 & 5 & 0.74 & $2.13(0.73-6.21)$ & 0.164 \\
\hline $\mathrm{CT}+\mathrm{TT}$ & 61 & 25.85 & 143 & 23.03 & $1.13(0.80-1.61)$ & 0.484 & 177 & 23.79 & $|5|$ & 22.24 & $1.12(0.86-1.44)$ & 0.408 \\
\hline $\mathrm{CC}+\mathrm{CT}$ & 234 & 99.15 & 615 & 99.03 & 1.00 & & 731 & 98.25 & 674 & 99.26 & 1.00 & \\
\hline TT & 2 & 0.85 & 6 & 0.97 & $0.83(0.16-4.22)$ & 0.825 & 13 & 1.75 & 5 & 0.74 & $2.14(0.74-6.23)$ & 0.162 \\
\hline T allele & 63 & 13.35 & 149 & 12.00 & & & 190 & 12.77 & 156 & 11.49 & & \\
\hline \multicolumn{13}{|c|}{ rs3087243 G>A } \\
\hline GG & 175 & 74.15 & 433 & 69.73 & 1.00 & & 462 & 62.10 & 417 & 61.41 & 1.00 & \\
\hline GA & 54 & 22.88 & 170 & 27.38 & $0.75(0.52-1.07)$ & 0.108 & 242 & 32.53 & 238 & 35.05 & $0.83(0.66-1.04)$ & 0.108 \\
\hline $\mathrm{AA}$ & 7 & 2.97 & 18 & 2.90 & $0.88(0.36-2.18)$ & 0.787 & 40 & 5.38 & 24 & 3.53 & $1.39(0.8 \mathrm{I}-2.39)$ & 0.234 \\
\hline $\mathrm{GA}+\mathrm{AA}$ & 61 & 25.85 & 188 & 30.27 & $0.80(0.57-1.13)$ & 0.208 & 282 & 37.90 & 262 & 38.59 & $0.90(0.72-1.13)$ & 0.368 \\
\hline $\mathrm{GG}+\mathrm{GA}$ & 229 & 97.03 & 603 & 97.10 & 1.00 & & 704 & 94.62 & 655 & 96.47 & 1.00 & \\
\hline $\mathrm{AA}$ & 7 & 2.97 & 18 & 2.90 & $0.99(0.40-2.42)$ & 0.974 & 40 & 5.38 & 24 & 3.53 & $1.51(0.89-2.59)$ & 0.130 \\
\hline A allele & 68 & $14.4 \mid$ & 206 & 16.59 & & & 322 & 23.71 & 286 & 21.06 & & \\
\hline \multicolumn{13}{|c|}{ rs733618 T>C } \\
\hline TT & 70 & 29.66 & 224 & 36.07 & 1.00 & & 276 & 37.10 & 234 & 34.46 & 1.00 & \\
\hline $\mathrm{TC}$ & 123 & 52.12 & 296 & 47.67 & $1.17(0.84-1.64)$ & 0.349 & 341 & 45.83 & 317 & 46.69 & $0.89(0.70-1.13)$ & 0.341 \\
\hline $\mathrm{CC}$ & 43 & 18.22 & 101 & 16.26 & $1.27(0.81-1.99)$ & 0.293 & 127 & 17.07 & 128 & 18.85 & $0.83(0.61-1.14)$ & 0.247 \\
\hline $\mathrm{TC}+\mathrm{CC}$ & 166 & 70.34 & 397 & 63.93 & $1.36(0.97-1.88)$ & 0.071 & 468 & 62.90 & 445 & 65.54 & $0.92(0.73-1.15)$ & 0.460 \\
\hline $\mathrm{TT}+\mathrm{TC}$ & 193 & 81.78 & 520 & 83.74 & 1.00 & & 617 & 82.93 & 551 & 81.15 & 1.00 & \\
\hline $\mathrm{CC}$ & 43 & 18.22 & 101 & 16.26 & $1.21(0.81-1.81)$ & 0.348 & 127 & 17.07 & 128 & 18.85 & $0.91(0.68-1.20)$ & 0.497 \\
\hline$C$ allele & 209 & 44.28 & 498 & 40.10 & & & 595 & 39.99 & 573 & 42.19 & & \\
\hline
\end{tabular}

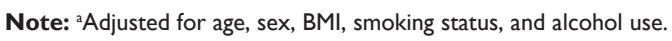

Abbreviations: $\mathrm{CRC}$, colorectal cancer; OR, odds ratio; $\mathrm{Cl}$, confidence interval; $\mathrm{BMI}$, body mass index.

$\mathrm{G}_{\mathrm{r} 30087243} \mathrm{C}_{\mathrm{rs} 16840252} \mathrm{~T}_{\mathrm{rs} 733618} \mathrm{~A}_{\mathrm{rs} 231775}$, and other haplotypes significantly increased the risk of CRC $(P<0.001,<0.001$, and 0.002, respectively, Table 6).

\section{Discussion}

The individual's susceptibility to CRC may be diverse, even with the same environmental exposure. Host genetic predisposition may lead to these differences. In recent years, several case-control studies have been performed to test the hypothesis that some functional variants in $C T L A-4$ and other immune checkpoint molecules such as $H L A-G$ may influence the risk and the treatment of CRC. ${ }^{30-36}$ Garziera et $\mathrm{al}^{36}$ reported that HLA-G 3'UTR polymorphisms might significantly affect the development of CRC. However, the association between CRC susceptibility and CTLA-4 polymorphisms remain conflicting. In addition, a comprehensive assessment was lacking. The aim of the present study was to identify the association between CTLA-4 tagging polymorphisms (rs3087243 G>A, rs16840252 C > T, rs733618 T>C, and rs $231775 \mathrm{G}>\mathrm{A}$ ) and susceptibility of CRC in a case-control study. Genotyping of 1,003 CRC cases and 1,303 cancer-free controls was carried out in an Eastern Chinese Han population. Our findings demonstrated that CTLA-4 rs $231775 \mathrm{G}>\mathrm{A}$ polymorphism might be associated with the risk of CRC. In a stratified analysis by primary site of tumor, the association was also found in colon cancer. When a subgroup analysis was performed by cohort, we also found CTLA-4 rs 231775 GA/AA genotypes might be associated with an increased 
Table 6 CTLA-4 haplotype frequencies (\%) in cases and controls and risk of CRC

\begin{tabular}{|c|c|c|c|c|c|c|}
\hline \multirow[t]{2}{*}{ Haplotypes } & \multicolumn{2}{|c|}{$\begin{array}{l}\text { CRC cases } \\
(n=2,006)\end{array}$} & \multicolumn{2}{|c|}{$\begin{array}{l}\text { Controls } \\
(n=2,606)\end{array}$} & \multirow[t]{2}{*}{$\begin{array}{l}\text { Crude OR } \\
(95 \% \mathrm{Cl})\end{array}$} & \multirow[t]{2}{*}{$P$-value } \\
\hline & $\mathbf{n}$ & $\%$ & $\mathbf{n}$ & $\%$ & & \\
\hline CTLA4 $\mathrm{G}_{\mathrm{r} s 3087243} \mathrm{C}_{\mathrm{rs} 16840252} \mathrm{C}_{\mathrm{r} 5733618} \mathrm{G}_{\mathrm{r} 5231775}$ & 765 & 39.11 & 1,069 & 41.15 & 1.00 & \\
\hline CTLA4 G $\mathrm{r}_{\mathrm{rs} 3087243} \mathrm{C}_{\mathrm{rs} 16840252} \mathrm{~T}_{\mathrm{rs} 733618} \mathrm{G}_{\mathrm{rs} 231775}$ & 490 & 25.05 & 726 & 27.94 & $0.94(0.81-1.09)$ & 0.437 \\
\hline CTLA4 A $\mathrm{r}_{\mathrm{r} 33087243} \mathrm{C}_{\mathrm{rs} 16840252} \mathrm{~T}_{\mathrm{rs} 733618} \mathrm{~A}_{\mathrm{rs} 2317775}$ & 382 & 19.53 & 492 & 18.94 & $1.08(0.92-1.28)$ & 0.326 \\
\hline CTLA4 $\mathrm{G}_{\mathrm{r} 33087243} \mathrm{~T}_{\mathrm{rs} 16840252} \mathrm{~T}_{\mathrm{rs} 533618} \mathrm{~A}_{\mathrm{r} 5231775}$ & 237 & 12.12 & 294 & 11.32 & $1.13(0.93-1.37)$ & 0.230 \\
\hline CTLA4 $\mathrm{G}_{\mathrm{rs} 3087243} \mathrm{C}_{\mathrm{rs} 16840252} \mathrm{C}_{\mathrm{rs} 5733618} \mathrm{~A}_{\mathrm{rs} 2317775}$ & 34 & 1.74 & 2 & 0.08 & $23.76(5.69-99.21)$ & $<0.001$ \\
\hline CTLA4 G $\mathrm{r}_{\mathrm{r} 3087243} \mathrm{C}_{\mathrm{rs} 16840252} \mathrm{~T}_{\mathrm{rs} 573618} \mathrm{~A}_{\mathrm{rs} 231775}$ & 26 & 1.33 & 5 & 0.19 & $7.27(2.78-19.01)$ & $<0.001$ \\
\hline Others & 22 & 1.12 & 10 & 0.38 & $3.07(1.45-6.53)$ & 0.002 \\
\hline
\end{tabular}

Abbreviations: CRC, colorectal cancer; OR, odds ratio; $\mathrm{Cl}$, confidence interval.

risk of $\mathrm{CRC}$ in the Zhenjiang cohort. Additionally, we found the CTLA-4 rs16840252 $\mathrm{C}>\mathrm{T}$ polymorphism was associated with a risk of colon cancer. Haplotype comparison analysis showed that CTLA4 $\mathrm{G}_{\mathrm{rs} 3087243} \mathrm{C}_{\mathrm{rs} 16840252} \mathrm{C}_{\mathrm{rs} 733618} \mathrm{~A}_{\mathrm{rs} 231775}$, $\mathrm{G}_{\mathrm{rs} 3087243} \mathrm{C}_{\mathrm{rs} 16840252} \mathrm{~T}_{\mathrm{rs} 733618} \mathrm{~A}_{\mathrm{rs} 231775}$, and other haplotypes increased the risk of CRC. Based on these primary findings, we found CTLA-4 tagging polymorphisms and haplotypes might influence the susceptibility to developing CRC.

Several case-control studies focused on the association between CTLA-4 rs16840252 C $>$ T polymorphism and risk of cancer. ${ }^{37,38}$ The observed results indicated that the CTLA-4 rs $16840252 \mathrm{C}>\mathrm{T}$ polymorphism might not confer a risk to cancer. However, CTLA-4 rs $16840252 \mathrm{C}>\mathrm{T}$ located in the promoter region of the CTLA4 gene. HapMap data suggest that CTLA-4 rs $16840252 \mathrm{C}>\mathrm{T}$ and $\mathrm{rs} 4553808 \mathrm{C}>\mathrm{T}(-1,661$ $\mathrm{C}>\mathrm{T}$ ) are in complete LD. ${ }^{37}$ Interestingly, Idris et al ${ }^{39}$ also reported that strong LD was found between CTLA-4 rs $16840252 \mathrm{C}>\mathrm{T}$ and rs5742909 $\mathrm{C}>\mathrm{T}(-318 \mathrm{C}>\mathrm{T})$ across all LD structures in an Asian population. In the presence of these functional SNPs on the same LD block, it could be that the predisposing allele of CTLA-4 rs $4553808 \mathrm{C}>\mathrm{T}$ or rs5742909 $\mathrm{C}>\mathrm{T}$ polymorphism is in $\mathrm{LD}$ with the protective allele of rs $16840252 \mathrm{C}>\mathrm{T}$. Ligers et $\mathrm{al}^{40}$ found that individuals carrying thymine at position -318 of the CTLA4 promoter (CTLA-4 rs5742909 C > T) showed significantly increased expression, both of CTLA-4 mRNA in non-stimulated cells and of cell-surface CTLA-4 after cellular stimulation. Recently, several meta-analyses indicated that CTLA-4 rs4553808 T $>$ C and rs5742909 $\mathrm{C}>\mathrm{T}$ polymorphisms were associated with the risk of cancer, especially in Asians. ${ }^{33,41,42}$ Since CTLA-4 rs16840252 C > T, rs5742909 C > T, and rs4553808 $\mathrm{T}>\mathrm{C}$ are in strong $\mathrm{LD}$, the function of CTLA-4 rs $16840252 \mathrm{C}>\mathrm{T}$ could be influenced by CTLA -4 rs 4553808 C $>$ T or rs5742909 C $>$ T. To the best of our knowledge, this case-control study was the first investigation to assess the association between CTLA-4 rs $16840252 \mathrm{C}>\mathrm{T}$ genotype and
CRC risk. Our findings indicated the CTLA-4 rs16840252 $\mathrm{C}>\mathrm{T}$ polymorphism represented a risk factor for colon cancer. Our findings are supported by those pool-analyses mentioned above.

The CTLA-4 rs $231775 \mathrm{G}>$ A polymorphism was the most frequently explored and was established as a functional SNP of the CTLA-4 gene. ${ }^{43,44}$ The CTLA-4 rs $231775 \mathrm{G}>\mathrm{A}$ (c.49 $\mathrm{G}>\mathrm{A})$ SNP causes p.17Ala $>17 \mathrm{Thr}$ change in the leading sequence of CTLA-4 receptor. ${ }^{40,44}$ Previous studies have demonstrated that the CTLA-4 rs $231775 \mathrm{G}$ allele has a lower mRNA efficiency and downregulates CTLA-4 protein more than the CTLA-4 rs231775 A allele. ${ }^{45}$ Therefore, individuals who carry the CTLA-4 rs231775 AA genotype have lower T-cell proliferation and immune response than those with the CTLA-4 rs231775 GG genotype. ${ }^{44}$ Sun et al ${ }^{43}$ also found that the p.17Ala $>17 \mathrm{Thr}$ substitution in CTLA-4 amino acid residue caused by the $c .49 \mathrm{G}>\mathrm{A}$ SNP significantly increased the interaction of the CTLA-4 receptor with its ligand B7.1, and recombinant CTLA-4-17Thr had a higher inhibitory effect to T-cell proliferation and immune response compared with CTLA-4-17Ala. These primary studies suggested that p.17Ala $>17 \mathrm{Thr}$ change in CTLA-4 may lead to a significant effect of T-cell proliferation and activation. A previous study demonstrated that donor CTLA-4 rs231775 genotype modulates the immune response to minor histocompatibility antigen mismatches. ${ }^{46}$ The CTLA-4 rs231775 genotype was also considered as a genetic determinant in autoimmune Addison's disease. ${ }^{47}$ Recently, a number of case-control studies focused on the relationship between CTLA-4 rs231775 $\mathrm{G}>\mathrm{A}$ SNP and the risk of cancer, and results of subsequent meta-analyses evidenced that the CTLA-4 rs $231775 \mathrm{G}>\mathrm{A}$ polymorphism was a risk factor for multiple cancer, especially in Asian populations. ${ }^{32-35}$ Three pooled-analysis studies also suggested that this polymorphism was associated with the development of CRC. ${ }^{15-17}$ Although these findings tried to suggest an association between CTLA-4 rs $231775 \mathrm{G}>\mathrm{A}$ 
polymorphism and CRC, the number of included studies and participants were limited. Thus, we conducted this casecontrol study with larger sample sizes to explore whether the CTLA-4 rs231775 G>A polymorphism was a risk factor for CRC. As demonstrated in Table 4, we found that this polymorphism was associated with an increased risk of CRC. We also studied the association of CTLA-4 rs231775 G>A polymorphism with CRC in different subgroups. Similar findings were also found when the Bonferroni correction was applied. The association was also significant in the colon cancer subgroup (AA vs GG: $\mathrm{OR}=1.61 ; 95 \% \mathrm{CI}=1.12-2.30$; $P=0.010$ and $\mathrm{AA}$ vs $\mathrm{GG} / \mathrm{GA}: \mathrm{OR}=1.59 ; 95 \% \mathrm{CI}=1.13-2.23$; $P=0.009$; Table 4). Results of the present study were in accordance with results of those meta-analyses and functional studies mentioned above.

CTLA-4 rs3087243 G>A, rs16840252 C>T, rs733618 $\mathrm{T}>\mathrm{C}$, and $\mathrm{rs} 231775 \mathrm{G}>\mathrm{A}$ variants may not be inherited randomly. As summarized in Table 6, we found the frequency of $\mathrm{G}_{\mathrm{rs} 3087243} \mathrm{C}_{\mathrm{rs} 16840252} \mathrm{C}_{\mathrm{rs} 733618} \mathrm{~A}_{\mathrm{rs} 231775}, \mathrm{G}_{\mathrm{rs} 3087243} \mathrm{C}_{\mathrm{rs} 16840252}$ $\mathrm{T}_{\mathrm{rr733618}} \mathrm{A}_{\mathrm{rs} 231775}$, and other haplotypes was significantly increased in CRC patients. We first reported the association of these $C T L A-4$ haplotypes with CRC susceptibility. A previous study suggested that the CTLA4 $\mathrm{G}_{\mathrm{r} 3087243} \mathrm{C}_{\mathrm{rs} 16840252}$ $\mathrm{C}_{\mathrm{rs} 733618} \mathrm{~A}_{\mathrm{rs} 231775}$ haplotype significantly increased the risk of gastric cardia adenocarcinoma, ${ }^{14}$ which was similar to our findings. However, these CTLA4 haplotypes only influenced a very minor fraction (less than $2 \%$ ) of the CRC patients.

Of note, we focused on the relationship of CTLA-4 tagging SNPs with CRC risk in an Eastern Chinese Han population. In addition, the sample size of our study was larger than before. Finally, the MAF in our controls was very similar to the data for Chinese in the database (Table 2).

Although there were some merits in our study, some limitations should also be addressed. First, this study was designed as a hospital-based investigation; the CRC patients and controls were recruited from hospitals in Eastern China and might not well represent the whole Eastern Chinese Han population. Second, the recruited CRC cases were moderate in stratified analyses. In the future, these findings should be verified in well-designed studies with a larger sample size. Third, because of the limited sample size of CRC patients and absence of a validation cohort, the power of the present study may be insufficient, especially in stratified analyses. Fourth, for insufficient samples, a replicated study was not conducted. Fifth, due to lack of other information, we did not carry out a further evaluation of potential interaction, such as dietary habit, family history, hormone level, intake of vitamins, other environmental factors, and lifestyles.
In considering the complexity of CRC etiology, the geneenvironment interaction should not be ignored. Finally, in our case-control study, we investigated four tagging SNPs in the CTLA-4 gene and did not focus on other functional SNPs. In the future, a fine-mapping study is needed to further identify any potential association.

\section{Conclusion}

In summary, the findings of our case-control study evidence that CTLA-4 rs16840252 $\mathrm{C}>\mathrm{T}$ and $\mathrm{rs} 231775 \mathrm{G}>\mathrm{A}$ SNPs are correlated with genetic susceptibility for development of CRC in an Eastern Chinese Han population. Additionally, this study first highlights that CTLA-4 rs16840252 C > T polymorphism increases the susceptibility of CRC. Furthermore, findings are consistent with the biological functions of tagging SNPs in the CTLA-4 gene and validate the hypothesis that CTLA-4 tagging polymorphisms, which alter CTLA-4 mRNA and/or protein expression, may influence normal immune functions and lead to an increased risk of CRC.

\section{Acknowledgments}

We appreciate all subjects who participated in this study. We wish to thank Dr Yan Liu (Genesky Biotechnologies Inc., Shanghai, China) for technical support. This study was supported by the Natural Science Foundation of Universities and colleges of Jiangsu Province (Grant No 16KJB310002), Senior Talents Scientific Research Foundation of Jiangsu University (Grant No 16JDG066), Critical Patented Project of the Science and Technology Bureau of Fujian Province (Grant No 2013YZ0002-2), the Special Program for the Development of Strategic Emerging Industries of Fujian Province (Grant No 13YZ0201), the Natural Science Foundation of Fujian Province (Grant No 2015J01435, 2017J01259), the Fujian Provincial Health and Family Planning Research Talent Training Program (Grant No 2015-CX-7, 2018-ZQN-13, 2016-1-11, 2018-1-1), the Joint Funds for the Innovation of Science and Technology, Fujian Province (Grant No 2017Y9077), and the National Clinical Key Specialty Construction Program.

\section{Disclosure}

The authors report no conflicts of interest in this work.

\section{References}

1. Chen W, Zheng R, Baade PD, et al. Cancer statistics in China, 2015 CA Cancer J Clin. 2016;66(2):115-132.

2. Torre LA, Bray F, Siegel RL, Ferlay J, Lortet-Tieulent J, Jemal A. Global cancer statistics, 2012. CA Cancer J Clin. 2015;65(2):87-108.

3. Jemal A, Bray F, Center MM, Ferlay J, Ward E, Forman D. Global cancer statistics. CA Cancer J Clin. 2011;61(2):69-90. 
4. Katsidzira L, Gangaidzo IT, Makunike-Mutasa R, et al. A case-control study of risk factors for colorectal cancer in an African population. Eur J Cancer Prev. Epub 2018 Apr 11:1.

5. Markowitz SD, Bertagnolli MM. Molecular origins of cancer: molecular basis of colorectal cancer. N Engl J Med. 2009;361(25):2449-2460.

6. Lichtenstein P, Holm NV, Verkasalo PK, et al. Environmental and heritable factors in the causation of cancer - analyses of cohorts of twins from Sweden, Denmark, and Finland. N Engl J Med. 2000;343(2):78-85.

7. Hemminki K, Chen B. Familial risk for colorectal cancers are mainly due to heritable causes. Cancer Epidemiol Biomarkers Prev. 2004; 13(7):1253-1256.

8. Hodi FS, Mihm MC, Soiffer RJ, et al. Biologic activity of cytotoxic T lymphocyte-associated antigen 4 antibody blockade in previously vaccinated metastatic melanoma and ovarian carcinoma patients. Proc Natl Acad Sci U S A. 2003;100(8):4712-4717.

9. Walunas TL, Lenschow DJ, Bakker CY, et al. CTLA-4 can function as a negative regulator of T cell activation. Immunity. 1994;1(5):405-413.

10. van der Merwe PA, Bodian DL, Daenke S, Linsley P, Davis SJ. CD80 (B7-1) binds both CD28 and CTLA-4 with a low affinity and very fast kinetics. J Exp Med. 1997;185(3):393-404.

11. Keilholz U. CTLA-4: negative regulator of the immune response and a target for cancer therapy. J Immunother. 2008;31(5):431-439.

12. Engelhardt JJ, Sullivan TJ, Allison JP. CTLA-4 overexpression inhibits T cell responses through a CD28-B7-dependent mechanism. J Immunol. 2006;177(2):1052-1061.

13. Teft WA, Kirchhof MG, Madrenas J. A molecular perspective of CTLA-4 function. Annu Rev Immunol. 2006;24:65-97.

14. Tang W, Wang Y, Chen S, et al. Investigation of cytotoxic T-lymphocyte antigen 4 polymorphisms in gastric cardia adenocarcinoma. Scand $J$ Immunol. 2016;83(3):212-218.

15. Wang L, Jing F, Su D, et al. Association between CTLA-4 rs 231775 polymorphism and risk of colorectal cancer: a meta analysis. Int J Clin Exp Med. 2015;8(1):650-657.

16. Wang Y, Wang X, Zhao R. The association of CTLA-4 A49G polymorphism with colorectal cancer risk in a Chinese Han population. Int J Immunogenet. 2015;42(2):93-99.

17. He L, Deng T, Luo HS. Association between cytotoxic T-lymphocyte antigen-4 +49A/G polymorphism and colorectal cancer risk: a metaanalysis. Int J Clin Exp Med. 2015;8(3):3752-3760.

18. Martin M, Schneider H, Azouz A, Rudd CE. Cytotoxic T lymphocyte antigen 4 and CD28 modulate cell surface raft expression in their regulation of T cell function. J Exp Med. 2001;194(11):1675-1682.

19. Chung KY, Gore I, Fong L, et al. Phase II study of the anti-cytotoxic T-lymphocyte-associated antigen 4 monoclonal antibody, tremelimumab, in patients with refractory metastatic colorectal cancer. J Clin Oncol. 2010;28(21):3485-3490.

20. Tang W, Zhang S, Qiu H, et al. Genetic variations in MTHFR and esophageal squamous cell carcinoma susceptibility in Chinese Han population. Med Oncol. 2014;31(5):915.

21. Zhai Y, Zhao WH, Chen CM. [Verification on the cut-offs of waist circumference for defining central obesity in Chinese elderly and tall adults]. Zhonghua Liu Xing Bing Xue Za Zhi. 2010;31(6):621-625.

22. Zhang X, Zhang S, Li Y, et al. Association of obesity and atrial fibrillation among middle-aged and elderly Chinese. Int J Obes. 2009;33(11): 1318-1325.

23. Carlson CS, Eberle MA, Kruglyak L, Nickerson DA. Mapping complex disease loci in whole-genome association studies. Nature. 2004;429(6990):446-452.

24. Zheng L, Yin J, Wang L, et al. Interleukin $1 \mathrm{~B}$ rs16944 G>A polymorphism was associated with a decreased risk of esophageal cancer in a Chinese population. Clin Biochem. 2013;46(15):1469-1473.

25. Yin J, Wang L, Shi Y, et al. Interleukin 17A rs4711998 A $>$ G polymorphism was associated with a decreased risk of esophageal cancer in a Chinese population. Dis Esophagus. 2014;27(1):87-92.

26. Yin J, Wang X, Wei J, et al. Interleukin 12 B rs3212227 T>G polymorphism was associated with an increased risk of gastric cardiac adenocarcinoma in a Chinese population. Dis Esophagus. 2015;28(3): 291-298.
27. Bland JM, Altman DG. Multiple significance tests: the Bonferroni method. BMJ. 1995;310(6973):170.

28. Lesack K, Naugler C. An open-source software program for performing Bonferroni and related corrections for multiple comparisons. J Pathol Inform. 2011;2:52.

29. Shi YY, He L, Shesis HL. SHEsis, a powerful software platform for analyses of linkage disequilibrium, haplotype construction, and genetic association at polymorphism loci. Cell Res. 2005;15(2):97-98.

30. Garziera M, Virdone S, de Mattia E, et al. HLA-G 3'UTR polymorphisms predict drug-induced G3-4 toxicity related to folinic acid/ 5-fluorouracil/oxaliplatin (FOLFOX4) chemotherapy in non-metastatic colorectal cancer. Int J Mol Sci. 2017;18(7):1366.

31. Garziera M, Bidoli E, Cecchin E, et al. HLA-G 3'UTR polymorphisms impact the prognosis of stage II-III CRC patients in fluoropyrimidinebased treatment. PLoS One. 2015;10(12):e0144000.

32. Zheng J, Yu X, Jiang L, et al. Association between the cytotoxic T-lymphocyte antigen $4+49 \mathrm{G}>\mathrm{A}$ polymorphism and cancer risk: a meta-analysis. BMC Cancer. 2010;10:522.

33. Geng R, Song F, Yang X, et al. Association between cytotoxic T lymphocyte antigen-4+49A/G, $-1722 \mathrm{~T} / \mathrm{C}$, and $-1661 \mathrm{~A} / \mathrm{G}$ polymorphisms and cancer risk: a meta-analysis. Tumour Biol. 2014;35(4):3627-3639.

34. Zhang Y, Zhang J, Deng Y, et al. Polymorphisms in the cytotoxic T-lymphocyte antigen 4 gene and cancer risk: a meta-analysis. Cancer. 2011;117(18):4312-4324.

35. Wang L, Jiang Z, Qiu H, Tang W, Duan T, Wang L. Associations between CTLA-4 +49 A/G (rs231775) polymorphism and cancer risk: a meta-analysis based on 52 case-control studies. Int J Clin Exp Med. 2015;8(5):6835-6851.

36. Garziera M, Catamo E, Crovella S, et al. Association of the HLA-G 3'UTR polymorphisms with colorectal cancer in Italy: a first insight. Int J Immunogenet. 2016;43(1):32-39.

37. Welsh MM, Applebaum KM, Spencer SK, Perry AE, Karagas MR, Nelson HH. CTLA4 variants, UV-induced tolerance, and risk of nonmelanoma skin cancer. Cancer Res. 2009;69(15):6158-6163.

38. Bouwhuis MG, Gast A, Figl A, et al. Polymorphisms in the CD28/ CTLA4/ICOS genes: role in malignant melanoma susceptibility and prognosis? Cancer Immunol Immunother. 2010;59(2):303-312.

39. Idris ZM, Miswan N, Muhi J, Mohd TA, Kun JF, Noordin R. Association of CTLA4 gene polymorphisms with lymphatic filariasis in an East Malaysian population. Hum Immunol. 2011;72(7):607-612.

40. Ligers A, Teleshova N, Masterman T, Huang WX, Hillert J. CTLA-4 gene expression is influenced by promoter and exon 1 polymorphisms. Genes Immun. 2001;2(3):145-152.

41. Yan Q, Chen P, Lu A, Zhao P, Gu A. Association between CTLA-4 $60 \mathrm{G} / \mathrm{A}$ and $-1661 \mathrm{~A} / \mathrm{G}$ polymorphisms and the risk of cancers: a metaanalysis. PLoS One. 2013;8(12):e83710.

42. Tang W. Relationship between cytotoxic T-lymphocyte antigen 4 (CTLA-4) rs5742909 C>T polymorphism and cancer risk: a metaanalysis based on thirty case-control studies. Int J Clin Exp Med. 2016; 9(8):15191-15203.

43. Sun T, Zhou Y, Yang M, et al. Functional genetic variations in cytotoxic T-lymphocyte antigen 4 and susceptibility to multiple types of cancer. Cancer Res. 2008;68(17):7025-7034.

44. Sun T, Hu Z, Shen H, Lin D. Genetic polymorphisms in cytotoxic T-lymphocyte antigen 4 and cancer: the dialectical nature of subtle human immune dysregulation. Cancer Res. 2009;69(15):6011-6014.

45. ChistiakovDA, Savost'anov KV, Turakulov RI, EfremovIA, DemurovLM. Genetic analysis and functional evaluation of the C/T(-318) and A/G(-1661) polymorphisms of the CTLA-4 gene in patients affected with Graves' disease. Clin Immunol. 2006;118(2-3):233-242.

46. Gallardo D, Bosch-Vizcaya A, Rodríguez-Romanos R, et al. Donor CTLA-4 genotype modulates the immune response to minor histocompatibility antigen mismatches. Biol Blood Marrow Transplant. 2017;23(12):2042-2047.

47. Wolff AS, Mitchell AL, Cordell HJ, et al. CTLA-4 as a genetic determinant in autoimmune Addison's disease. Genes Immun. 2015;16(6): 430-436. 
OncoTargets and Therapy

\section{Publish your work in this journal}

OncoTargets and Therapy is an international, peer-reviewed, open access journal focusing on the pathological basis of all cancers, potential targets for therapy and treatment protocols employed to improve the management of cancer patients. The journal also focuses on the impact of management programs and new therapeutic agents and protocols on

patient perspectives such as quality of life, adherence and satisfaction. The manuscript management system is completely online and includes a very quick and fair peer-review system, which is all easy to use. Visit http://www.dovepress.com/testimonials.php to read real quotes from published authors.

Submit your manuscript here: http://www.dovepress.com/oncotargets-and-therapy-journal 